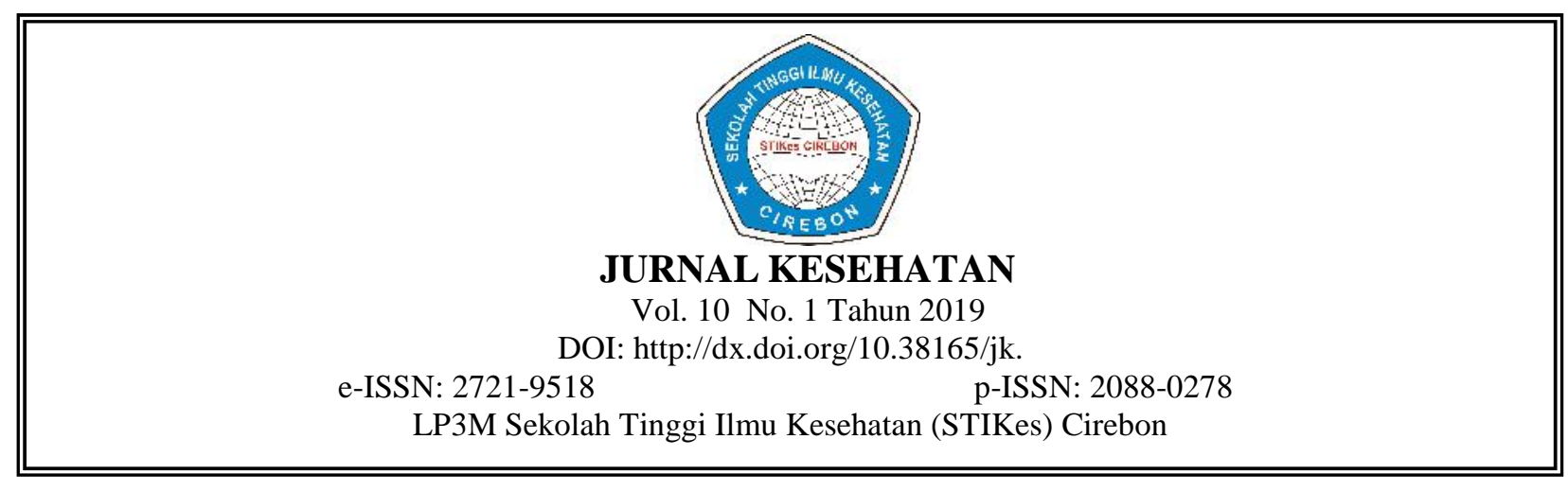

\title{
PENGARUH PENINGKATAN MUTU TERHADAP KUALITAS PELAYANAN LABORATORIUM
}

\author{
Destu Satya Widyaningsih* \\ Program Studi D3 Analis Kesehatan Manggala Yogyakarta \\ destu.satya@gmail.com \\ Irma Susilowati** \\ Program Studi D3 Analis Kesehatan Manggala Yogyakarta
}

\begin{abstract}
Abstrak
Puskesmas Kotagede II Yogyakarta selalu menjaga keramahan dan kepercayaan yang baik kepada pasien untuk meningkatkan dan menjaga kualitas pelayanan sesuai dengan harapan pasien. Hal ini dibuktikan dengan jurnal tahun 2017 dengan hasil bahwa terdapat pengaruh kualitas pelayanan terhadap kepuasan pasien. Studi pendahuluan yang juga dilakukan oleh peneliti pada tanggal 13 Januari 2018 dan didapatkan hasil bahwa petugas laboratorium di Puskesmas Kotagede II memiliki suatu kendala dalam menangani pasien, hal ini dikarenakan hanya ada satu petugas di laboratorium dengan jumlah pasien yang banyak. Akan tetapi data kunjungan pasien ke laboratorium Puskesmas Kotagede II Yogyakarta bulan November 2017 sebanyak 335 pasien, dan pada bulan Desember 2017 sebanyak 341 pasien, maka terjadi kenaikan sekitar $1,76 \%$. Kenaikan tersebut salah satunya berasal dari mutu yang diukur sebelumnya. Jenis penelitian ini termasuk penelitian kuantitatif dengan pendekatan cross sectional. Populasi penelitian sebanyak 341 pasien dan sampel penelitian berjumlah 78 responden. Metode pengumpulan data dengan teknik wawancara dan instrument yang digunakan adalah kuesioner. Analisa data menggunakan uji data kuantitatif yaitu uji statistik regresi linier sederhana yang ditinjau dari lima dimensi yaitu: tampilan fisik (tangible), kehandalan (realibility), daya tanggap (responsiviness), jaminan (assurance), dan empati (emphaty). Hasil penelitian didapatkan bahwa Ha diterima dan Ho ditolak yang berarti ada pengaruh peningkatan mutu terhadap kualitas pelayanan laboratorium di UPT Puskesmas Kotagede II Yogyakarta yang dapat ditunjukkan dengan nilai signifikansi sebesar 0,000. Semakin meningkatnya peningkatan mutu maka semakin meningkat pula kualitas pelayanan di laboratorium UPT Puskesmas Kotagede II Yogyakarta.
\end{abstract}

Kata Kunci: Mutu, Kualitas Pelayanan, Laboratorium, Puskesmas.

\begin{abstract}
The Kotagede II Primary Health Care (PHC) of Yogyakarta has always been providing hospitality and keeping patients' trust in order to maintain standard quality of service, as previous study demonstrated that the level of service quality was associated with patient satisfaction. Another study showed that there was a problem in the laboratory unit of Kotagede II PHC in providing service to patients mainly due to huge number of patients with limited number of laboratory staff. An increase in number of patients seeking services in the laboratory unit of Kotagede II PHC (335 to 341; 1.76\%) was reported from November 2017 to December 2017, and such increase might be due to increasing quality of services provided by the laboratory staff. Current study aimed to identify association of quality improvement and service quality in the laboratory unit of Kotagede II PHC of Yogyakarta. The quantitative study implemented a cross-sectional design, including a total of 78 patients as respondents. Methods of collecting data with interview techniques and the instruments used were questionnaires. Data analysis was performed by using linear regression, analyzed from five aspects: reliability, responsiveness, assurance, empathy, and tangible. Current study results demonstrated that quality improvement is associated with service quality level $(P<0.001)$. In conclusion, improvements in quality is followed by improvements in service quality level in the laboratory unit of Kotagede II PHC of Yogyakarta. Keywords: quality improvement, service quality, laboratory unit, primary health care
\end{abstract}




\section{PENDAHULUAN}

Puskesmas Kotagede II selalu menjaga keramahan dan kepercayaan yang baik kepada pasien untuk meningkatkan dan menjaga kualitas pelayanan sesuai dengan harapan pasien. Berdasarkan hasil studi pendahuluan yang dilakukan oleh peneliti pada tanggal 13 Januari 2018 dan didapatkan hasil, bahwa petugas laboratorium di Puskesmas Kotagede II memiliki suatu kendala dalam menangani pasien, hal ini dikarenakan hanya ada satu petugas di laboratorium dengan jumlah pasien yang banyak. Data kunjungan pasien ke laboratorium Puskesmas Kotagede II bulan November 2017 sebanyak 335 pasien, dan pada bulan Desember 2017 sebanyak 341 pasien, maka terjadinya kenaikan kunjungan pelayanan di laboratorium Puskesmas Kotagede II.

Konsep peningkatan mutu berkelanjutan yaitu lebih menekankan pada pendakatan analitik dan secara bersamaan melaksanakan peningkatan mutu untuk mengatasi kelemahan-kelemahan yang ada pada pelayanan kesehatan. ${ }^{1}$

Pendapat mengenai dimensi atau ukuran kualitas pelayanan dikemukanakan oleh Tjiptono (1997) dalam bukunya "Prinsip tentang total quality service". ${ }^{2}$ Kelima dimensi mutu tersebut, meliputi: (1) tampilan fisik (tangible), yaitu meliputi fasilitas fisik, perlengkapan, pegawai, dan sarana komunikasi, (2) kehandalan (realibility), yaitu kemampunan memberikan pelayanan yang dijanjikan dengan segara, akurat, dan memuaskan, (3) daya tanggap (responsiveness), yaitu keinginan para staf untuk membantu para pelanggan dan memberikan pelayanan dengan tanggap, (4) jaminan (assurance), yaitu mencangkup pengetahuan, kemampuan, kesopanan, dapat dipercaya, bebas dari bahaya, dan resiko atau keragu-raguan, (5) empati (emphaty), yaitu kemudahan dalam melakukan hubungan komunikasi yang baik, perhatian pribadi, dan memahami kebutuhan pelanggan.Tujuan dari penelitian ini adalah untuk mengetahui pengaruh peningkatan mutu terhadap kualitas pelayanan laboratorium di UPT Puskesmas Kotagede II Yogyakarta.

\section{METODE PENELITIAN}

Jenis penelitian ini menggunakan penelitian deskriptif kuantitatif dengan metode cross sectional. Penelitian cross sectional dilakukan dengan cara pendekatan, wawancara, dan pengumpulan data menggunakan kuesioner. Penelitian yang mampu menjelaskan hubungan antara satu variabel dengan variabel lain pada populasi yang diteliti, yang digunakan untuk melihat pengaruh peningkatan mutu terhadap kualitas pelayanan laboratorium di UPT Puskesmas Kotagede II Yogyakarta. ${ }^{3}$

Populasi penelitian di UPT Puskesmas Kotagede II Yogyakarta pada bulan Desember 2017 sebanyak pasien dengan 341 orang. Sampel adalah subset (bagian) populasi yang dipilih dengan cara tertentu sehingga dianggap dapat mewakili populasinya. ${ }^{4}$

Dalam rumus ini diperoleh sebagai berikut:

$$
\mathrm{n}=\frac{N}{1+0,10^{2} \times N}
$$

Keterangan :

$\mathrm{n}$ : sampel yang diinginkan

$\mathrm{N}$ : jumlah populasi

Dari rumus tersebut dapat diketahui jumlah sampel yang dibutuhkan dalam penelitian ini adalah :

$$
\begin{aligned}
& \mathrm{n}=\frac{N}{1+0,10^{2} \times N} \\
& \mathrm{n}=\frac{341}{1+0,01 \times 341} \\
& \mathrm{n}=77,3 \text { sampel, karena minimal maka diambil } 78 \text { sampel }
\end{aligned}
$$

Jadi sampel yang diperlukan dalam penelitian ini adalah 78 sampel dengan taraf kesalahan 10\% ini untuk pengambilan sambel acak sederhana tidak termasuk pasien anak-anak dan lansia. ${ }^{5}$

Teknik pengumpulan data merupakan cara pengumpulan data yang dibutuhkan dalam penelitian. Data primer menjadi data yang dipilih dalam mengumpulkan data karena data primer 
dapat diperoleh melalui pengumpulan kuesioner dari responden setelah mendapatkan pelayanan laboratorium di UPT Puskesmas Kotagede II. Analisa data pada penelitian ini dengan metode uji statistic regresi linier sederhana.

\section{HASIL PENELITIAN}

Dalam penelitian yang menggunakan uji analisis regresi linear berganda didapatkan hasil seperti yang ditunjukkan pada tabel berikut ini:

Tabel 1. Tabel Regresi Linier Sederhana

\begin{tabular}{cccc}
\hline No & Nilai & Koefesien & Signifikansi \\
\hline 1 & Konstanta & 36.664 & 0.000 \\
2 & Peningkatan Mutu & 0.800 & 0.000 \\
\hline
\end{tabular}

Berdasarkan Tabel diatas perhitungan regresi linear berganda dengan menggunakan program SPSS didapat hasil sebagai berikut:

$$
\mathrm{Y}=36.644+0.800 \mathrm{X} 1
$$

1) Konstanta $=36.644$

Artinya jika tidak ada variabel peningkatan mutu yang mempengaruhi kualitas pelayanan, maka kualitas pelayanan sebesar 36.644 satuan.

2) $b=0.800$

Artinya jika Variabel peningkatan mutu meningkat sebesar satu satuan maka kualitas pelayanan akan meningkat sebesar 0.800 .

Hasil pengujian analisis regresi linear sederhana menunjukkan bahwa terdapat nilai signifikansi sebesar $0.000(0.003<0,05)$. Nilai tersebut dapat membuktikan bahwa Ha diterima dan Ho ditolak yang berarti bahwa "Ada pengaruh peningkatan mutu terhadap kualitas pelayanan laboratorium di UPT Puskesmas Kotagede II Yogyakarta“. Adapun hasil koefisien determinasi $(r$ square), bisa ditunjukkan pada table 2 berikut:

Tabel 2. Tabel Koefisien Determinasi

\begin{tabular}{cc}
\hline No & Koefesien determinan $(\%)$ \\
\hline 1 & 0.377 \\
\hline
\end{tabular}

Berdasarkan analisis regresi linear sederhana besarnya koefisien determinasi ( $r$ square $)=$ 0,377 , artinya variabel bebas secara mempengaruhi variabel terikat sebesar $37,7 \%$ sisanya sebesar $62,3 \%$ dipengaruhi oleh variabel lain yang tidak dimasukkan dalam model penelitian.

\section{PEMBAHASAN}

Peningkatan mutu dapat meningkat dilihat dengan meningkatnya kualitas pelayanan yang dilihat dari lima dimensi mutu, hal ini berjalan dengan hasil penelitian ini menunjukkan bahwa sebagian besar responden menyatakan puas dengan kualitas pelayanan yang ada di laboratorium Puskesmas Kotagede II Yogyakarta yang dapat dibuktikan dengan nilai pada kualitas pelayanan meningkat sebesar 0,800 jika peningkatan mutu meningkat sebesar satu, hal ini menunjukkan bahwa ada pengaruh antara peningkatan mutu terhadap kualitas pelayanan laboratorium di UPT Puskesmas Kotagede II Yogyakarta, dengan nilai signifikansi didapat sebesar 0,000 yang lebih kecil daripada 0,05 .

Kualitas pelayanan yang mencangkup pelayanan tampilan fisik, pelayanan kehandalan, pelayanan daya tanggap, pelayanan jaminan dan pelayanan empati. Peningkatan mutu dapat meningkat dilihat dengan meningkatnya kualitas pelayanan yang dilihat dari lima dimensi mutu, 
maka dari kelima dimensi tersebut memiliki nilai skor yang didapatkan dari pengisian kuesioner yang dibagikan kepada pasien yang berkunjung di laboratorium puskesmas. Kelima dimensi kualitas pelayanan sebagai berikut :

1. Dimensi tampilan fisik memiliki nilai skor puas yang diberikan oleh pasien dari pengisian kuisioner, maka pasien dapat merasakan kenyamanan saat berada di ruang tunggu.

2. Dimensi kehandalan memiliki skor sangat puas yang diberikan oleh pasien dari pengisian kuisioner, maka pasien dapat merasakan keterampilan petugas dalam melakukan pelayanan kepada pasien.

3. Dimensi daya tanggap memiliki skor puas yang diberikan oleh pasien dari pengisian kuisioner, maka pasien dapat merasakan kepedulian yang dilihat dari respon yang diberikan oleh petugas untuk pasien.

4. Dimensi jaminan memiliki skor yang sangat puas yang diberikan oleh pasien dari pengisian kuisioner, maka pasien dapat merasakan pelayanan keamanan yang diberikan petugas dan jaminan biaya yang cukup membantu untuk kategori pasien yang sudah lanjut usia.

5. Dimensi empati memiliki skor yang kurang puas yang diberikan oleh pasien dari pengisian kuisioner, maka pasien dapat merasakan bahwa dari sikap petugas dalam pelayanan kurang ramah, dan memberikan hasil pemeriksaan yang tidak tepat waktu.

Dari kelima dimensi kualitas pelayanan diatas bahwa skor masih kurang pada sikap petugas, maka untuk itu puskesmas untuk meningkatkan kualitas pelayanan terutama melalui petugas dengan lebih memahami keluhan, dan bersikap ramah kepada pasien, serta melakukan pelayanan yang tepat waktu.

Mutu pelayanan kesehatan berkaitan dengan standar yang telah ditetapkan maka dapat dihubungkan dengan lingkungan, sikap, tingkah laku dari pemberi pelayanan dalam memberikan pelayanan kesehatan dengan cara berkomunikasi dengan baik kepada pasien atau pelangggan. ${ }^{6}$

Adanya pelayanan yang baik, nyaman, kepercayaan, dan keramahan yang diberikan oleh petugas laboratorium membuat pasien untuk datang kembali ke puskesmas, dalam keadaan sakit ataupun dalam rangka mencegah suatu penyakit. ${ }^{7}$

\section{SIMPULAN}

Berdasarkan penelitian ini maka dapat diambil kesimpulan bahwa Ha diterima dan Ho ditolak yang berarti ada pengaruh peningkatan mutu terhadap kualitas pelayanan laboratorium di UPT Puskesmas Kotagede II Yogyakarta yang dapat ditunjukkan dengan nilai signifikansi sebesar 0,000. Semakin meningkatnya peningkatan mutu maka semakin meningkat pula kualitas pelayanan di laboratorium UPT Puskesmas Kotagede II Yogyakarta.

\section{SARAN}

Hasil penelitian ini dapat digunakan sebagai masukkan bagi puskesmas untuk meningkatan kualitas pelayanan yang ada dilaboratorium yang dapat dilihat dari segi empati yaitu memahami dan merespon setiap keluhan pasien, bersikap lebih ramah kepada pasien.

\section{DAFTAR PUSTAKA}

1. Bustami, M.S. Penjaminan mutu pelayanan kesehatan dan akseptabilitasnya. Padang: Erlangga; 2011.

2. Hardiansyah. Manajemen pelayanan dan pengembangan organisasi publik. Yogyakarta: Gava media; 2017.

3. Sugiyono. Metode penelitian kuantitatif kualitatif dan R\&D. Bandung: Alfabeta; 2014.

4. Susilani T, Emiliana, dan Wibowo A, Trisno. Dasar-dasar penelitian untuk mahasiswa kesehatan. Yogyakarta: Graha Cendikia; 2015.

5. Sugiyono. Metode penelitian kuantitatif kualitatif dan R\&D Ed.3. Bandung: Alfabeta; 2017.

6. Azwar, Azrul. Pedoman menjaga mutu pelayanan kesehatan. Jakarta; 1995.

7. PERMENKES No.75.Tentang pusat kesehatan masyarakat. Jakarta; 2014. 